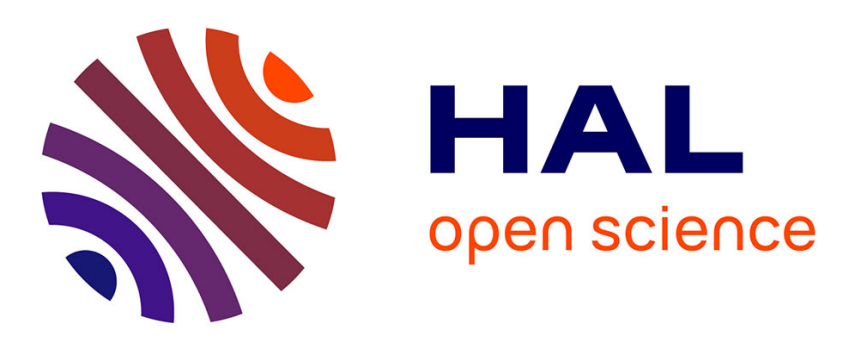

\title{
Robust Obstacle Detection based on Dense Disparity Maps
}

Wided Miled, Jean-Christophe Pesquet, Michel Null Parent

\section{To cite this version:}

Wided Miled, Jean-Christophe Pesquet, Michel Null Parent. Robust Obstacle Detection based on Dense Disparity Maps. Eleventh International Conference on Computer Aided Systems Theory EUROCAST 2007, Feb 2007, Las Palmas de Gran Canaria, Canary Islands / Espagne. inria-00129750

\section{HAL Id: inria-00129750 \\ https://hal.inria.fr/inria-00129750}

Submitted on 8 Feb 2007

HAL is a multi-disciplinary open access archive for the deposit and dissemination of scientific research documents, whether they are published or not. The documents may come from teaching and research institutions in France or abroad, or from public or private research centers.
L'archive ouverte pluridisciplinaire HAL, est destinée au dépôt et à la diffusion de documents scientifiques de niveau recherche, publiés ou non, émanant des établissements d'enseignement et de recherche français ou étrangers, des laboratoires publics ou privés. 


\title{
Robust Obstacle Detection based on Dense Disparity Maps
}

\author{
Wided Miled $^{1,2}$, Jean Christophe Pesquet ${ }^{2}$ and Michel Parent ${ }^{1}$ \\ ${ }^{1}$ INRIA, IMARA Team, Domaine de Voluceau, 78150 Le Chesnay Cedex, France \\ \{wided.miled,michel.parent\}@inria.fr \\ ${ }^{2}$ Institut Gaspard Monge / UMR-CNRS 8049, Université Marne-la-Vallée, 77454 \\ Champs-sur-Marne, France, pesquet@univ-mlv.fr
}

Obstacle detection is an important component for many autonomous vehicle navigation systems. Several methods for obstacle detection have been proposed using various active sensors such as radar, sonar and laser range finders. Vision based techniques have the advantage of low cost and provide a large amount of information about the environment around an intelligent vehicle. This paper deals with the development of an accurate and efficient vision based obstacle detection method which relies on a wavelet analysis. The development system will be integrated on the Cybercar platform which is a road vehicle with fully automated driving capabilities [1].

\section{Stereo vision configuration}

The video acquisition system adopted on the Cybercar is the Bumblebee stereo vision system from Point Grey Research. It contains two pre-calibrated digital CCD cameras in an epipolar configuration. This configuration is usually achieved in practice by rectifying the stereo images based on intrinsic and extrinsic parameters of the cameras [2. The epipolar geometry constraint reduces the correspondence problem from two dimensions to one, by involving that corresponding pairs of image elements always occur on homologous epipolar lines. In this case, the disparity $d$ is calculated as the horizontal displacement between the reference pixel in the left image and the candidate pixel in the right image. Given two corresponding pixels $p_{l}=\left(x_{l}, y_{l}\right)$ and $p_{r}=\left(x_{r}, y_{r}\right)$ in the left and right images, respectively, the disparity is given by $d=x_{l}-x_{r}$. The depth information can then be calculated by triangulation:

$$
Z=\frac{b \cdot f}{d},
$$

where $b$ is the length of the baseline and $f$ is the focal length.

\section{Disparity map estimation}

Stereovision is the process of obtaining the depth information of a scene from a pair of left and right views. It involves finding corresponding pixels in both images, leading to the so-called disparity map. Many matching approaches have been proposed including feature-based and area-based approaches. The featurebased approach provides accurate information and has a low computational cost. However, the resulting depth information is sparse and an interpolation step is required to estimate depth across surfaces in the scene. Area based methods on 
the other hand produce dense disparity maps, which is mandatory in the obstacle detection, but often fail at depth discontinuities and in textureless areas. Another difficulty for area based methods arises from lighting variations between both images, which may occur in outdoor environment and can largely degrade the performance of the depth recovery.

In this paper, we propose a new dense disparity field estimation approach that avoids many of the limitations mentioned above. To deal with illumination variations often encountered in practice, we develop a spatially varying multiplicative model that accounts for brightness changes between both images in the stereo pair. The stereo matching problem based on this model is then formulated as a constrained optimization problem in which an appropriate objective function is minimized under convex constraints. These constraints arise from prior knowledge and rely on various properties of the field to be estimated. In disparity estimation, one would like to smooth isotropically inside homogeneous regions and preserve discontinuities around object edges 3 . This can be achieved with the help of a suitable regularization constraint. In this work, we investigate a regularization constraint based on image transformed coefficients. Since wavelets provide a simple characterization of a wide variety of function smoothness spaces, the regularization constraint is defined as a (semi-)norm in an appropriate image space, that can efficiently model signals with sharp discontinuities.

The resulting multi-constrained optimization problem is solved via an efficient block iterative algorithm which allows to combine both wavelet and spatial domain constraints 4. In addition, this algorithm is well suited for an implementation on parallel processors which helps in reducing the computational time.

\section{Obstacle detection based on disparity image analysis}

The ability to detect obstacles and the degree of danger is essential for vehicle navigation. The technique used in this paper for obstacle detection takes advantage of the reliability of the 3D information obtained from the preliminary disparity estimation stage. To reduce the computational cost, we propose to extract and reduce the estimation to a part of the image which corresponds to the road surface. Furthermore, based on the observation that most obstacles are vertical and that the road is mostly horizontal, we develop a directional wavelet transform to capture efficiently these geometrical structures characterized by the horizontal and vertical directions.

\section{References}

1. M. Parent and A. De La Fortelle. Cybercars : Past, present and future of the technology. ITS World Congress 2005, 2005.

2. A. Fusiello, E. Trucco, and A. Verri. A compact algorithm for rectification of stereo pairs. Machine Vision and Applications, 12(1):16-22, 2000.

3. W Miled, J. C. Pesquet, and M. Parent. Wavelet-constrained regularization for disparity map estimation. Eur. Sig. and Imag. Proc. Conference, Sept 2006, Best Student Paper Award.

4. P. L. Combettes and J. C. Pesquet. Wavelet-constrained image restoration. Int. Journal of Wavelets, Multiresolution and Information Proc., 2:371-389, Dec. 2004. 